\title{
A Framework of Critical Success Factors and Success Criteria for Structural Works of a Mixed-Use Building Construction Project
}

\author{
Vien Carlo M. Amora ${ }^{1, *}$, Joseph Berlin P. Juanzon² \\ ${ }^{1}$ School of Graduate Studies, Mapúa University, Intramuros, Manila, 1002, Philippines \\ ${ }^{2}$ School of Civil, Environmental and Geological Engineering, Mapúa University, Intramuros, Manila, 1002, Philippines
}

Received August 4, 2021; Revised November 25, 2021; Accepted December 13, 2021

\section{Cite This Paper in the following Citation Styles}

(a): [1] Vien Carlo M. Amora, Joseph Berlin P. Juanzon, "A Framework of Critical Success Factors and Success Criteria for Structural Works of a Mixed-Use Building Construction Project," Civil Engineering and Architecture, Vol. 10, No. 1, pp. 267-279, 2022. DOI: 10.13189/cea.2022.100123.

(b): Vien Carlo M. Amora, Joseph Berlin P. Juanzon (2022). A Framework of Critical Success Factors and Success Criteria for Structural Works of a Mixed-Use Building Construction Project. Civil Engineering and Architecture, 10(1), 267-279. DOI: 10.13189/cea.2022.100123.

Copyright $\mathrm{C} 2022$ by authors, all rights reserved. Authors agree that this article remains permanently open access under the terms of the Creative Commons Attribution License 4.0 International License

\begin{abstract}
The need to determine the critical success factors (CSFs) and success criteria (SC) would serve as keys to an effective and efficient project delivery and performance to achieve project success. This paper analyzed the CSFs and SC through the application of Pareto Analysis and Analytic Hierarchy Process using a validated questionnaire as a basis in developing a framework for structural works of a mixed-use building construction project through the determination of priority CSFs and most recognized SC. Based on the results, the study found twenty-six CSFs associated with structural works of building project delivery using meta-analysis. The top six CSFs were established as the vital few or the 20 percent after performing Pareto Analysis. Utilizing a validated questionnaire, experts evaluated CSFs through the fundamental scale of the Analytic Hierarchy Process which revealed the ranking of most prioritized CSFs such as Teamwork and Communication, Training and Education, Personnel, Project Mission, Top Management Commitment, and Client Focus, respectively. Furthermore, the study determined the five most recognized SC with the highest frequency on existing literature such as Client/Customer Satisfaction, Cost - Budget, Time Schedule, Quality - Performance, and Other Stakeholder's Satisfaction. With this, a framework has been developed based on priority CSFs and recognized SC that can be used by construction project participants during the structural
\end{abstract}

phase and may serve as a guide to achieve the utmost objective of all construction projects which is success.

Keywords Project Success, Critical Success Factors, Success Criteria, Analytic Hierarchy Process

\section{Introduction}

\subsection{The Background of the Study}

The success of a project is believed to be the utmost objective in all business industries, certainly in construction. Traditionally, the definition of success is the degree where goals and expectations are being met. However, numerous construction projects continue failing to succeed, unable to fulfill commitments or schedules, exceed project costs, unable to meet quality requirements, and create disappointing outcomes even on the early stage of the construction phase due to different factors. Thus, it is significant to determine these factors that can hamper the success of a project which are also known as critical success factors or CSFs [1]. The knowledge on CSFs in construction projects is one of the keys to an effective and efficient project delivery and performance. Together with project success, they are considered as a means for the 
improvement of project effectiveness [2]. Aside from CSFs, the project success concept can be evaluated based on the performance measures from various success criteria or SC. These SC are used to measure success whilst CSFs facilitate the achievement of success [3]. To define and measure the success of a project, there are several success criteria to be identified. Thorough determination and assessment of CSFs and SC would perfectly define the project success. But according to Turner [4], CSFs cannot be determined if the $\mathrm{SC}$ were not defined and identified at the beginning of the project. Therefore, ascertaining both the CSFs and SC of a project right at the initial stage can achieve the greatest objective of a project, which is the success [5].

\subsubsection{Project Success}

Every construction project has a set of objectives to fulfill which serves as their respective performance standard measurement [6]. Success should take into consideration the different perspectives of entities as well as the goals that relate to different varieties of elements such as social, technical, education, financial and professional issues [7,8]. As mentioned, success is goal-oriented or is measured based on goal attainment, a project can still be completed on time within budget but considered as a failed project if it did not meet company strategic objectives [5].

Moreover, project success is considered as a strategic management concept wherein the short and long-term goal for the project is aligned with the project efforts [9]. Some projects have increased the complexity level which makes strategic project management to become a progressive critical issue for project success [10]. Strategic management perspective can be considered as one of the criteria for project success. This will determine the strengths, gaps, and priorities of a project. The gaps will be filled by identifying the variances between the organization that is destined to succeed and the one that is destined to ride the waves of the marketplace.

\subsubsection{Critical Success Factors}

The importance of determining CSFs benefits the success in achieving project objectives. The knowledge on CSFs in construction projects is one of the keys to an effective and efficient project delivery and performance [11]. Together with project success criteria, they are considered as a means for the improvement of project effectiveness [2]. CSFs are defined as factors predicting success on projects. These signify the components that may hamper the success of a certain project [1].

\subsubsection{Success Criteria}

Success criteria are used to measure success whilst success factors facilitate the achievement of success [3]. Formerly, different literature defines that the criteria for project success are acknowledged through the golden triangle of time, budget, and required quality [12]. Achieving the project schedule, budget cost, and expected quality are being used to evaluate the construction project performance [6].

As time goes by, several researchers have endorsed that project success cannot be measured through the three criteria only - time, cost, and quality. The best overall criterion for project success is when the user, project manager, and system development group unanimously think their expectations were met or exceeded [13].

Projects can be affected by different conflicts concerning success criteria and it is recommended that success criteria must be agreed upon by all project participants or parties before the execution and implementation of a project [14]. The success of future projects will progressively be assessed by the criteria of strategy, sustainability, and safety [15].

Success criteria frequently change based on project participants, service scope, project size, technological implications, owner's sophistication to facility designs, and a diversity of other factors [3]. Moreover, success criteria also demand to consider the perceptions and expectations of the stakeholders such as owners, architects, engineers, contractors, and other project participants.

The relationship of CSFs and success criteria for enhancing project success is an important aspect to capture lessons learned [16]. Thorough determination and assessment of project success criteria would perfectly define the project success. CSFs cannot be determined if success criteria were not defined and identified at the beginning of the project [4]. Herewith, the project success can be concluded as more complete if both success factors and success criteria are taken into consideration as a whole [17].

\subsection{Research Objective}

The main objective of this study is to develop a framework for structural works of a mixed-use building construction project based on CSFs and project SC to improve overall efficiency in project delivery and implementation. This framework could also serve as a guide in establishing unity of purpose between all project participants in achieving the utmost objective of all construction projects which is success.

Moreover, based on the research objective stated above, this study aims to address the following:

1. Determine the critical success factors associated with structural works of building project delivery and perform Pareto Analysis to identify the most significant critical success factors.

2. Establish the significant project success criteria related to building projects.

3. Perform Analytic Hierarchy Process (AHP) to the identified priority critical success factors and analyze 
its relationship to the established project success criteria.

4. Develop and propose a framework for structural works of building construction projects to standardize their project implementation and performance that would lead to project success.

The framework will benefit future construction projects to be more organized right from the beginning and improve strategic management concepts.

\subsection{Scope and Limitation}

It has been proven in previous literature and studies that there are significant changes on success factors as well as on criteria across the stages of construction [18], however, this study only focuses on determining the factors and criteria over the structural phase of a construction, from substructure to superstructure phase. During the conduct of the research project, the data are limited to the works of the general contractor. The study also does not seek to include the factors that are beyond the control of the project participants such as calamities, force majeures, etc.

\section{Research Methodology}

The approach to achieve the research's main objective was based on the conceptual framework as shown in Figure 1. It is composed of four (4) phases and nine (9) systematic steps to achieve the aim of the study. The study had utilized mixed methods research, which is both qualitative and quantitative in nature.

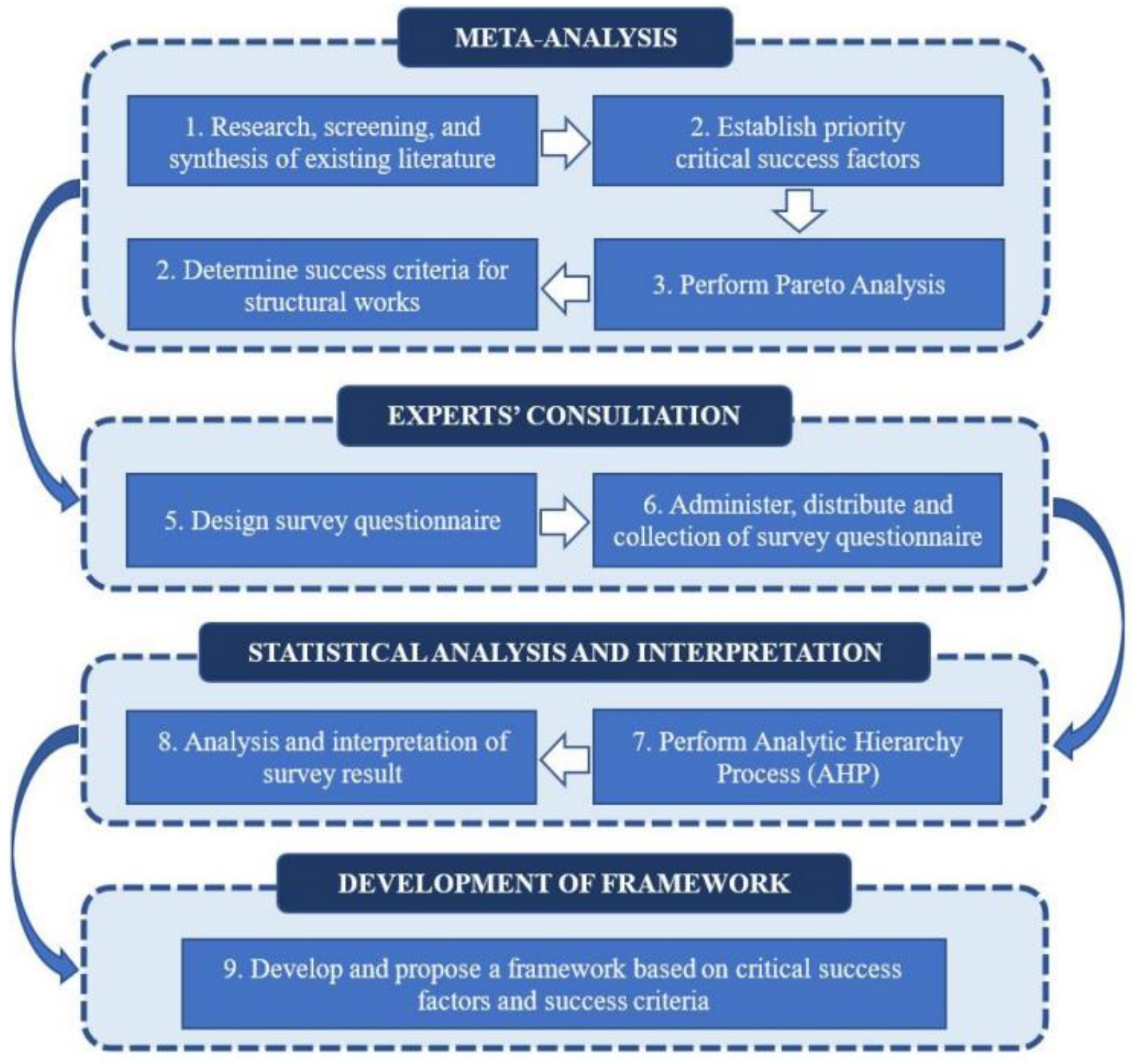

Figure 1. Conceptual Framework 


\subsection{Research Setting}

The study was established primarily in a first-class urbanized city geographically situated at the Southern Manila District of National Capital Region, Philippines. The location was chosen since various value-enhancing projects have been developed and currently emerging in the city. Thus, it is ideal to study the success factors and criteria for various developments within the area. Particularly, the construction development project is composed of nine independent 4-storey sustainable mixed-used or commercial development with basement and service deck. It has a total lot area of 49,136.00 square meters and total construction floor area of $137,656.72$ square meters.

\subsection{Meta-Analysis}

The research methodology had utilized the Meta-Analysis to identify and determine all CSFs and SC necessary and appropriate for structural phase of mixed-use building construction project. Meta-Analysis is a comprehensive or systematic review and a statistical procedure where data are being collected from different existing studies.

For SC, the study determined the five most recognized $\mathrm{SC}$ with highest frequency and appeared ten times or more in existing literature.

\subsubsection{Pareto Analysis}

A statistical technique by Pareto [19] was utilized to determine the priority CSFs among all identified factors from previous literature. Pareto Analysis is also called as the $80 / 20$ rule, and it is a technique in decision making that generates a significant overall effect from the selection of limited number of tasks [19]. It separates the vital few from trivial many. The vital few focus on the twenty percent crucial factors, while the trivial many are responsible for the remaining eighty percent factors.

From the pool of CSFs based on their frequency, Pareto Analysis reduced the number of CSFs to 20 percent, and these were categorized as the priority CSFs. Procedures involved in computing the vital few or the 20 percent of the CSFs are as follows:

1. A vertical bar chart was created. The $\mathrm{x}$-axis of the chart represents the pool of CSFs while the y-axis represents the total score of an individual CSF.

2. CSFs along the $\mathrm{x}$-axis were arranged in descending order from left to right of the axis based on its frequency on the gathered related literature.

3. The cumulative count for each CSF was also arranged in descending order.

4. The cumulative count percentages (CCP) were calculated and plotted with the vertical bar chart starting from the CSF with the highest frequency. The $\mathrm{CCP}$ was computed by dividing the total score of an individual CSF with the summation of all CSFs.
5. A second y-axis was created having a percentage from $0 \%$ to $100 \%$.

6. The CCP were plotted and connected to form a curve.

7. A line at $80 \%$ on the second $y$-axis was drawn parallel to the $\mathrm{x}$-axis. A point of intersection between the line and the curve formed by connecting the $\mathrm{CCP}$ was then identified. A line is dropped from the point of intersection. This line separates the vital few on the left side of the graph and the trivial many on the right side of the graph.

\subsection{Experts' Consultation}

The conduction of experts' consultation through the development and administering of validated survey questionnaire was the second phase of research methodology. The survey questionnaire was designed and developed based on the result from the Pareto Analysis and was distributed to and collected from the experts supervising and controlling the construction project.

The survey questionnaire is divided into three (3) parts. The first part of the survey questionnaire is the invitation to partake in the survey. For the second part of the survey, it includes the demographics or profile of the experts such as gender, age, highest educational attainment, years of professional experience, project organization category, and job description. The last part of the survey questionnaire comprises the multi-criteria analysis for the identified priority CSFs after utilizing Pareto Analysis.

According to Fei \& Khan [20], experts should have the following criteria: (a) at least 30 years old; (b) more than 10 years of professional experience; and (c) stay in a particular company for more than 10 years. With these criteria for competence and reliability, the respondents leading the project team organizations were chosen such as project managers and project heads.

\subsection{Statistical Analysis: Analytic Hierarchy Process}

The study utilized Analytic Hierarchy Process or AHP as a statistical tool which was developed by Thomas L. Saaty in 1980. It is an effective, flexible, and powerful tool for complex decision making which benefits the decision maker to establish priorities and attain the best decision [21]. Any complex problem can be decomposed into several sub-problems using AHP in terms of hierarchical levels where each level represents a set of criteria or attributes relative to each sub-problem [22].

Moreover, AHP was used to calculate priority weights in multi-attribute decision-making situations to achieve the objective of this study. One of the objectives is to apply the principles and techniques of the analytic hierarchy process in the prioritization and selection of critical success factors with regards to successful project delivery and implementation of structural works. As defined by Saaty [21], decision making is a cognitive and 
mental process derived from most possible adequate selection based on tangible and intangible criteria which are chosen by those who make the decisions [23].

To properly utilize AHP as statistical tool, the study observed the step-by-step procedure as follows as cited in $[21,24,25]$ :

1. Define the research goals.

2. Develop the hierarchical structure which consists of research goals located at the top, followed by the major criteria of problems to be identified and lastly the sub-criteria which detailed the set of alternatives.

3. Construct a set of $\mathrm{n} \times \mathrm{n}$ pairwise comparison matrices for each of the criteria or alternatives of the lower levels of hierarchical structure. With these comparisons, the relative importance of the elements and the number of times an element are important that the other will be identified. The priority scale suggested by Saaty [22] was used to compare the said elements as shown in Table 1.

Table 1. Pairwise Comparison Scale of AHP

\begin{tabular}{|c|c|}
\hline $\begin{array}{c}\text { IMPORTANCE } \\
\text { LEVEL }\end{array}$ & EXPERT JUDGEMENT \\
\hline 1 & Equally \\
\hline 2 & Equally to moderately \\
\hline 3 & Moderately \\
\hline 4 & Moderately to strongly \\
\hline 5 & Strongly \\
\hline 6 & Strongly to very strongly \\
\hline 7 & Very strongly \\
\hline 8 & Very strongly to extremely \\
\hline 9 & Extremely \\
\hline
\end{tabular}

4. There are $n(n-1) / 2$ judgments required to develop the set of matrices in Step 3. Reciprocals are automatically assigned in each pairwise comparison.

5. Hierarchical synthesis is now used to weigh the eigenvectors (priority vector) by the weights of the criteria and the sum is taken over all weighted eigenvector entries corresponding to those in the next lower level of the hierarchy.

6. The consistency of comparisons is measured by utilizing the eigenvalue $\left(\mathrm{\gamma}_{\max }\right)$ after all pairwise comparisons have been completed. A consistency index (CI) is calculated with the eigenvalue with the formula of:

$$
C I=\frac{\left(\gamma_{\max }-n\right)}{(n-1)}
$$

Where, $\mathrm{n}=$ matrix size

7. The judgement on the consistency can be checked through the consistency ratio (CR) of CI with the appropriate value of random consistency index (RI). The RI appropriate for the size of the matrix is shown in Table 2. Based on Saaty [21], CR is acceptable when it does not exceed 0.10 . When CR is greater than 0.10 , the judgment matrix should be considered inconsistent. The judgement is suggested to be reviewed and repeated to obtain a consistent matrix $[26,27]$.

Table 2. Random Consistency Index [28]

\begin{tabular}{|c|c|}
\hline MATRIX SIZE & RANDOM CONSISTENCY \\
\hline 1 & 0.00 \\
\hline 2 & 0.00 \\
\hline 3 & 0.58 \\
\hline 4 & 0.90 \\
\hline 5 & 1.12 \\
\hline 6 & 1.24 \\
\hline 7 & 1.32 \\
\hline 8 & 1.41 \\
\hline 9 & 1.45 \\
\hline 10 & 1.49 \\
\hline
\end{tabular}

\section{Results and Discussion}

\subsection{Critical Success Factors and Success Criteria}

The study found a total of 519 CSFs and it was observed that most of the factors share the same context, therefore, algorithm for combining and reorganizing should be provided to create a more concise and well comprehensive of list CSFs. The organized CSFs from the results of the research, screening, and synthesis of the existing literature were reduced to $26 \mathrm{CSFs}$ as shown in Table 3. 
Table 3. Comprehensive List of Critical Success Factors

\begin{tabular}{|c|c|c|}
\hline DESIGNATION & $\begin{array}{c}\text { CRITICAL SUCCESS } \\
\text { FACTORS }\end{array}$ & FREQUENCY \\
\hline CSF 1 & Top Management Support & 90 \\
\hline CSF 2 & Personnel & 67 \\
\hline CSF 3 & Project Mission & 56 \\
\hline $\mathrm{CSF} 4$ & Client Focus & 55 \\
\hline CSF 5 & $\begin{array}{l}\text { Teamwork and } \\
\text { Communication }\end{array}$ & 55 \\
\hline CSF 6 & Training and Education & 47 \\
\hline CSF 7 & Resource Allocation & 46 \\
\hline CSF 8 & Project Schedule/ Plans & 15 \\
\hline CSF 9 & Monitoring and Feedback & 9 \\
\hline CSF 10 & Technical Tasks & 9 \\
\hline CSF 11 & Continuous Improvement & 9 \\
\hline CSF 12 & $\begin{array}{c}\text { Coordination among } \\
\text { Various Parties }\end{array}$ & 8 \\
\hline CSF 13 & External Factors & 8 \\
\hline CSF 14 & Financial Management & 7 \\
\hline CSF 15 & Urgency & 7 \\
\hline CSF 16 & Troubleshooting & 6 \\
\hline CSF 17 & Organizational Culture & 5 \\
\hline CSF 18 & Risk Management & 5 \\
\hline CSF 19 & Power and Politics & 4 \\
\hline CSF 20 & Site Management & 3 \\
\hline CSF 21 & Safety Management & 2 \\
\hline CSF 22 & $\begin{array}{c}\text { Project Uniqueness, } \\
\text { Importance, and Public } \\
\text { Exposure }\end{array}$ & 2 \\
\hline CSF 23 & $\begin{array}{c}\text { Clear and Precise Briefing } \\
\text { Documents }\end{array}$ & 1 \\
\hline CSF 24 & Internal Factors & 1 \\
\hline CSF 25 & $\begin{array}{c}\text { Construction Control } \\
\text { Meetings }\end{array}$ & 1 \\
\hline CSF 26 & $\begin{array}{c}\text { Company Wide } \\
\text { Acceptance }\end{array}$ & 1 \\
\hline
\end{tabular}

The study established the priority CSFs using Pareto Analysis. The CCP of each CSFs is shown in Table 4 wherein there are six CSFs identified as the vital few or the 20 percent from Pareto Analysis. The CSFs within the vital few are Top Management Support, Personnel, Project Mission, Client Focus, Teamwork and Communication, and Training and Education.
Table 4. Pareto Analysis for CSFs

\begin{tabular}{|c|c|c|}
\hline DESIGNATION & CUMULATIVE & CCP \\
\hline CSF 1 & 90 & $17.34 \%$ \\
\hline CSF 2 & 157 & $30.25 \%$ \\
\hline CSF 3 & 213 & $41.04 \%$ \\
\hline CSF 4 & 268 & $51.64 \%$ \\
\hline CSF 5 & 323 & $62.24 \%$ \\
\hline CSF 6 & 370 & $71.29 \%$ \\
\hline CSF 7 & 416 & $80.15 \%$ \\
\hline CSF 8 & 431 & $83.04 \%$ \\
\hline CSF 9 & 440 & $84.78 \%$ \\
\hline CSF 10 & 449 & $86.51 \%$ \\
\hline CSF 11 & 458 & $88.25 \%$ \\
\hline CSF 12 & 466 & $89.79 \%$ \\
\hline CSF 13 & 474 & $91.33 \%$ \\
\hline CSF 14 & 481 & $92.68 \%$ \\
\hline CSF 15 & 488 & $94.03 \%$ \\
\hline CSF 16 & 494 & $95.18 \%$ \\
\hline CSF 17 & 499 & $96.15 \%$ \\
\hline CSF 18 & 504 & $97.11 \%$ \\
\hline CSF 19 & 508 & $97.88 \%$ \\
\hline CSF 20 & 511 & $98.46 \%$ \\
\hline CSF 21 & 513 & $98.84 \%$ \\
\hline CSF 22 & 515 & $99.23 \%$ \\
\hline CSF 23 & 516 & $99.42 \%$ \\
\hline CSF 24 & 517 & $99.61 \%$ \\
\hline CSF 25 & 518 & $99.81 \%$ \\
\hline CSF 26 & 519 & $100.00 \%$ \\
\hline
\end{tabular}

For the pool of SC from meta-analysis (see Appendix), the study found a total of 128 criteria. Same as CSFs, criteria were combined and re-organized to create a more concise and well comprehensive list of SC. The five (5) most recognized SC with the highest frequency or appeared ten (10) times or more in existing literature were chosen. These SC are Client/Customer Satisfaction, Cost-Budget, Time-Schedule, Quality-Performance, and Other Stakeholder's Satisfaction. 


\subsection{Experts' Consultation}

The experts, as research's respondents, were selected from the project participants based on their organization or category such as client, consultant, and contractor. Their information and qualifications for the category of expert were gathered and only five respondents have satisfied the criteria to be categorized as an expert. All experts are male, 30 years old and above, have more than 10 years of professional experience, and finished bachelor's degree. Moreover, for the project organization category and job description of these experts, one is a project manager from the client, one is a project manager form the consultant, one is a senior project manager form the contractor, and the two are project heads from the contractor.

\subsection{Statistical Analysis and Interpretation}

Upon performing the AHP and from the comparison matrix, the weights for each compared element or criterion were calculated. The random consistency index (RI) that has been used is 1.24 corresponding to the size of the matrix. The value of the consistency ratio (CR) was calculated based on the Eigenvalue, CI, and RI.

Individual pairwise comparison matrix was developed for each expert to compare the results and ranking prior to consolidation of all completed research surveys. The matrices of the client, consultant, and contractor are shown in Table 5, 6, and 7, respectively. This also shows the calculated weights and parameters and CSF ranking of each project participants category. The computed CR were 8.177 percent for the client-side, 3.839 percent for the consultant-side, and 3.177 percent for the contractor-side which completely does not exceed 10 percent, thus, this signifies that the judgements of the experts are consistent.

Table 5. Pairwise Comparison Matrix of Client

\begin{tabular}{|c|c|c|c|c|c|c|c|c|}
\hline \multicolumn{7}{|c|}{ CLIENT-SIDE } & \multirow{2}{*}{\multicolumn{2}{|c|}{$\begin{array}{l}\text { WEIGHT \& } \\
\text { RANKING }\end{array}$}} \\
\hline CSF & 1 & 2 & 3 & 4 & 5 & 6 & & \\
\hline 1 & 1.000 & 1.000 & 7.000 & 7.000 & 7.000 & 5.000 & $39.27 \%$ & 1 \\
\hline 2 & 1.000 & 1.000 & 5.000 & 5.000 & 5.000 & 5.000 & $32.64 \%$ & 2 \\
\hline 3 & 0.143 & 0.200 & 1.000 & 1.000 & 7.000 & 1.000 & $10.60 \%$ & 3 \\
\hline 4 & 0.143 & 0.200 & 1.000 & 1.000 & 1.000 & 1.000 & $6.18 \%$ & 5 \\
\hline 5 & 0.143 & 0.200 & 0.143 & 1.000 & 1.000 & 1.000 & $4.79 \%$ & 6 \\
\hline 6 & 0.200 & 0.200 & 1.000 & 1.000 & 1.000 & 1.000 & $6.53 \%$ & 4 \\
\hline SUM & 2.63 & 2.80 & 15.14 & 16.00 & 22.00 & 14.00 & & \\
\hline \multicolumn{5}{|c|}{ Eigenvalue } & \multicolumn{4}{|c|}{6.507} \\
\hline \multicolumn{5}{|c|}{ Random Consistency Index (RI) } & \multicolumn{4}{|c|}{1.240} \\
\hline \multicolumn{5}{|c|}{ Consistency Index $(\mathrm{CI})$} & \multicolumn{4}{|c|}{0.1014} \\
\hline \multicolumn{5}{|c|}{ Consistency Ratio (CR) } & \multicolumn{4}{|c|}{$8.177 \%$} \\
\hline
\end{tabular}

Table 6. Pairwise Comparison Matrix of Consultant

\begin{tabular}{|c|c|c|c|c|c|c|c|c|}
\hline \multicolumn{7}{|c|}{ CONSULTANT-SIDE } & \multirow{2}{*}{\multicolumn{2}{|c|}{$\begin{array}{l}\text { WEIGHT \& } \\
\text { RANKING }\end{array}$}} \\
\hline CSF & 1 & 2 & 3 & 4 & 5 & 6 & & \\
\hline 1 & 1.000 & 0.200 & 0.200 & 1.000 & 0.140 & 0.140 & $3.79 \%$ & 6 \\
\hline 2 & 5.000 & 1.000 & 1.000 & 7.000 & 0.330 & 1.000 & $19.54 \%$ & 4 \\
\hline 3 & 5.000 & 1.000 & 1.000 & 7.000 & 1.000 & 1.000 & $22.61 \%$ & 2 \\
\hline 4 & 1.000 & 0.143 & 0.143 & 1.000 & 0.200 & 0.330 & $4.31 \%$ & 5 \\
\hline 5 & 7.000 & 3.000 & 1.000 & 5.000 & 1.000 & 1.000 & $28.70 \%$ & 1 \\
\hline 6 & 7.000 & 1.000 & 1.000 & 3.000 & 1.000 & 1.000 & $21.06 \%$ & 3 \\
\hline SUM & 26.00 & 6.34 & 4.34 & 24.00 & 3.67 & 4.47 & & \\
\hline \multicolumn{5}{|c|}{ Eigenvalue } & \multicolumn{4}{|c|}{6.238} \\
\hline \multicolumn{5}{|c|}{ Random Consistency Index (RI) } & \multicolumn{4}{|c|}{1.240} \\
\hline \multicolumn{5}{|c|}{ Consistency Index (CI) } & \multicolumn{4}{|c|}{0.0476} \\
\hline \multicolumn{5}{|c|}{ Consistency Ratio (CR) } & \multicolumn{4}{|c|}{$3.839 \%$} \\
\hline
\end{tabular}


Table 7. Pairwise Comparison Matrix of Contractor

\begin{tabular}{|c|c|c|c|c|c|c|c|c|}
\hline \multicolumn{7}{|c|}{ CONTRACTOR-SIDE } & \multirow{2}{*}{\multicolumn{2}{|c|}{$\begin{array}{l}\text { WEIGHT \& } \\
\text { RANKING }\end{array}$}} \\
\hline CSF & 1 & 2 & 3 & 4 & 5 & 6 & & \\
\hline 1 & 1.000 & 0.580 & 1.090 & 1.000 & 0.130 & 0.150 & $5.50 \%$ & 5 \\
\hline 2 & 1.710 & 1.000 & 2.470 & 2.920 & 0.170 & 0.410 & $11.29 \%$ & 3 \\
\hline 3 & 0.920 & 0.405 & 1.000 & 1.710 & 0.170 & 0.220 & $6.24 \%$ & 4 \\
\hline 4 & 1.000 & 0.342 & 0.585 & 1.000 & 0.150 & 0.330 & $5.41 \%$ & 6 \\
\hline 5 & 7.612 & 6.000 & 5.739 & 6.804 & 1.000 & 2.470 & $46.81 \%$ & 1 \\
\hline 6 & 6.804 & 2.410 & 4.610 & 3.000 & 0.405 & 1.000 & $24.75 \%$ & 2 \\
\hline SUM & 19.05 & 10.74 & 15.49 & 16.43 & 2.03 & 4.58 & & \\
\hline \multicolumn{5}{|c|}{ Eigenvalue } & \multicolumn{4}{|c|}{6.197} \\
\hline \multicolumn{5}{|c|}{ Random Consistency Index (RI) } & \multicolumn{4}{|c|}{1.240} \\
\hline \multicolumn{5}{|c|}{ Consistency Index (CI) } & \multicolumn{4}{|c|}{0.0394} \\
\hline \multicolumn{5}{|c|}{ Consistency Ratio (CR) } & \multicolumn{4}{|c|}{$3.177 \%$} \\
\hline
\end{tabular}

Table 8. Consolidated Pairwise Comparison Matrix

\begin{tabular}{|c|c|c|c|c|c|c|c|c|}
\hline \multicolumn{7}{|c|}{ CONSOLIDATED } & \multirow{2}{*}{\multicolumn{2}{|c|}{$\begin{array}{l}\text { WEIGHT \& } \\
\text { RANKING }\end{array}$}} \\
\hline CSF & 1 & 2 & 3 & 4 & 5 & 6 & & \\
\hline 1 & 1.000 & 0.530 & 1.120 & 1.480 & 0.300 & 0.300 & $9.20 \%$ & 5 \\
\hline 2 & 1.904 & 1.000 & 2.370 & 3.880 & 0.380 & 0.810 & $18.95 \%$ & 3 \\
\hline 3 & 0.889 & 0.422 & 1.000 & 2.040 & 0.520 & 0.400 & $10.63 \%$ & 4 \\
\hline 4 & 0.678 & 0.258 & 0.491 & 1.000 & 0.230 & 0.420 & $6.40 \%$ & 6 \\
\hline 5 & 3.380 & 2.646 & 1.933 & 4.360 & 1.000 & 1.720 & $32.51 \%$ & 1 \\
\hline 6 & 3.380 & 1.229 & 2.502 & 2.408 & 0.582 & 1.000 & $22.31 \%$ & 2 \\
\hline SUM & 11.231 & 6.085 & 9.416 & 15.168 & 3.012 & 4.65 & & \\
\hline \multicolumn{5}{|c|}{ Eigenvalue } & \multicolumn{4}{|c|}{6.169} \\
\hline \multicolumn{5}{|c|}{ Random Consistency Index (RI) } & \multicolumn{4}{|c|}{1.240} \\
\hline \multicolumn{5}{|c|}{ Consistency Index (CI) } & \multicolumn{4}{|c|}{0.0338} \\
\hline \multicolumn{5}{|c|}{ Consistency Ratio (CR) } & \multicolumn{4}{|c|}{$2.704 \%$} \\
\hline
\end{tabular}

Lastly, the results from the pairwise comparison matrix of all experts were consolidated to determine the overall priority CSFs based on their weight and ranking. From the performance of AHP, the consolidated results of priority CSFs as shown in Table 8 are ranked as follows: CSF 5-Teamwork and Communication with $32.51 \%$, CSF 6-Training and Education with $22.31 \%$, CSF 2-Personnel with $18.95 \%$, CSF 3-Project Mission with $10.63 \%$, CSF 1-Top Management Commitment with 9.20\%, and CSF 4-Client Focus with $6.40 \%$. This calculated a CR of $2.704 \%$ which is considered as a consistent judgement.

\subsection{Development of Framework Critical Success Factors and Success Criteria}

Project success can be compared to a bull's eye, which is defined as the center of the target. Similar to the project participants, these professionals only aim for success. The developed framework as shown in Figure 2 is divided into three segments: the Construction Project Participants, the Critical Success Factors, and the Success Criteria. Each segment involves participation and goals to achieve project success. Construction projects are composed of client, consultants, and contractors, and these three groups of participants cover all factors and have the same goals on how to accomplish respective projects. Interactions between these participants perform an important role to provide effective and efficient project delivery and implementation. These interactions should be focused more on dealing with the prioritized critical success factors since this is the "how to achieve" the utmost objective of a project.

The CSF that ranked first is teamwork and communication, which means any message or information shall be effectively conveyed by any forms of communication during project implementation. Teamwork is the collaborative effort of a group to accomplish a common goal and achieve togetherness in the most 
effective and efficient way possible. The second CSF is about training and education which entails the formal and systematic training that must be received by the employees to understand the project goals and mission and how a system works for the project. Training shall be done by all personnel in the organization as achieving quality in the construction is the responsibility of everyone in the organization. The third CSF, personnel, that focuses on the proper recruitment, selection, and training of the necessary personnel for the project team. The fourth CSF is about the project mission that refers to the initial clarity of goals and general directions for the project. The first step in the project development process is to know what it is one wishes to develop, what the project's capabilities are, why the project is needed and how it will benefit those who use it. The fifth is top management commitment which involves top management to be committed in establishing unity of purpose and direction of the organization by creating and maintaining an internal environment in which people can be fully involved in meeting all the organization's objectives. Lastly, client focus which is about the understanding and taking care of client's specific needs and expectations by providing products and services that effectively address them.

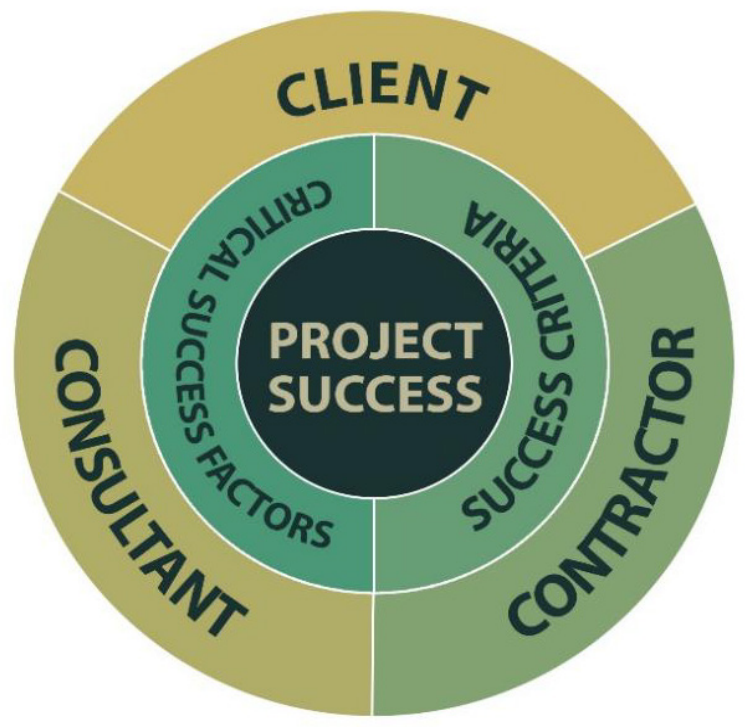

Figure 2. Framework of Critical Success Factors and Success Criteria for Structural Works of a Mixed-Use Building Construction Project

Organizations gain competitive advantage by increasing the value to customers in one or more activities, relative to what competitors offer. With all these priority critical success factors, construction project participants should be able to know the "what to achieve" at the end of construction.

To provide quality service exceeding expectations that certainly defines success, objective and subjective measures will serve as the guide for project participants. Client, consultants, and contractors shall be focused on delivering works that will satisfy the client as well as other stakeholders, accomplish project within the allocated budget and schedule, and provide quality requirements for the project. These criteria will lead to project success that needs greater effort when simultaneously monitored and achieved during project implementation.

\section{Conclusion and Recommendations}

Numerous construction projects fail to succeed, fulfill commitments, and create disappointing outcomes even on the early stage of the construction phase. However, project success can still be achieved if CSFs and SC will be identified right before the initial stage of the project and be prioritized and monitored during project implementation. The need to determine these factors and criteria serves as keys to an effective and efficient project delivery and performance. Moreover, all stakeholders will be confident in attaining both project success and project management success. In this study, a framework for structural works of a building construction project based on the identified priority CSFs and SC during the structural phase was developed.

In relation to the specific objectives of the study and the attained results from the conducted survey and statistical tools, the following conclusions were derived:

i. Based on meta-analysis, the study identified twenty-six CSFs associated to structural works of building project delivery and after performing Pareto Analysis, the six priority CSFs were determined namely: Top Management Support, Personnel, Project Mission, Client Focus, Teamwork and Communication, and Training and Education.

ii. The study determined the five most recognized success criteria with the highest frequencies on existing literature specifically: Client/Customer Satisfaction, Cost-Budget, Time-Schedule, Quality-Performance, and Other Stakeholder's Satisfaction.

iii. The consolidated ranking of priority CSFs is as follows: Teamwork and Communication, Training and Education, Personnel, Project Mission, Top Management Commitment, and Client Focus.

iv. Based on the established CSFs and SC from meta-analysis, experts' consultation, and application of Pareto Analysis and Analytic Hierarchy Process, the study developed a framework that can be considered by all project participants in the construction as well as to future projects that have the same processes and organizations. Project organizations need greater effort in considering factors and criteria during project implementation to deliver effective and 
efficient quality of works and service. This can certainly serve as a guide to monitor critical factors and focus on criteria that would lead to project success.

Furthermore, from the results of individual organization, client is more focused on the commitment and support of top management while consultant and contractors believe that success can be hampered if teamwork and communication are not being established within project organization. On the contrary, client-side ranked teamwork and communication as the least critical success factor while consultant and contractors placed top management commitment as the fifth and sixth CSF, respectively. This suggests that the client who is involved in key project decisions will need the commitment of the top management to achieve project success. While the consultants who are the intermediary between the client and contractor believe that project participants must have good teamwork and effective communication to establish a successful project. However, top management commitment and teamwork and communication are not the only factors critical to the success; thus, the lower ranked factors shall not also be disregarded. Care and attention need to be paid to these factors and if disregarded, there may be a serious risk of project failure.

It is indeed significant to define and identify SC at the beginning of the project to determine CSFs. Project success can be concluded as more complete if both factors and criteria in success are taken into consideration simultaneously. Project could be considered failure if all CSFs were monitored yet success criteria were not met. With the six priority CSFs identified, project organization must focus on delivering works that will satisfy the client as well as other stakeholders, accomplish project within the allocated budget and schedule, and provide quality requirements for the project.
For further studies, the inclusion of works prior and after to structural works or specifically project life cycle is highly recommended to explore. This project life cycle includes initiating, planning, executing, monitoring and controlling, and closing. More so, it is recommended to assess the success criteria identified in meta-analysis such as environment impact and health and safety. Recognizing the effects of these criteria towards project success and through project participants would certainly cause significant impact more especially in this time of pandemic. The subject matter of this study is limited to analysis and investigation of the structural phase only, but the framework developed could be applied to various types of construction projects most especially structural works with the presence of project participant's category as highlighted in this study.

\section{Acknowledgments}

The author expresses his gratitude first and foremost to God Almighty for the knowledge, strength, and grace to finish the study. To DOST - Science Education Institute (DOST-SEI) and Engineering Research and Development for Technology (ERDT), Mapúa University Graduate Studies, and School of Civil, Environmental and Geological Engineering for the continuous support and assistance to finish the Graduate School. To the respondents who shared their expertise during the conduct of the survey. And lastly, to Mrs. Viena Clariz A. Salvacion, Ar. Vernice A. Ambojia, Ms. Luzviminda G. Amora, and Ms. Abianne Vernon A. Reyes for the support and encouragement shared throughout the conduct of the research study. 


\section{APPENDIX}

Comprehensive List of Success Criteria

\begin{tabular}{|c|c|c|}
\hline DESIGNATION & SUCCESS CRITERIA & FREQUENCY \\
\hline $\mathrm{SC} 1$ & Client/Customer Satisfaction & 16 \\
\hline $\mathrm{SC} 2$ & Cost - Budget & 11 \\
\hline $\mathrm{SC} 3$ & Time - Schedule & 10 \\
\hline $\mathrm{SC} 4$ & Quality - Performance & 10 \\
\hline $\mathrm{SC} 5$ & Other Stakeholders' Satisfaction & 10 \\
\hline $\mathrm{SC} 6$ & Environmental Impact & 6 \\
\hline $\mathrm{SC} 7$ & Health And Safety & 5 \\
\hline $\mathrm{SC} 8$ & Project Team & 4 \\
\hline SC 9 & Scope & 2 \\
\hline $\mathrm{SC} 10$ & Technical Performance & 2 \\
\hline SC 11 & Profitability & 2 \\
\hline $\mathrm{SC} 12$ & Functionality & 2 \\
\hline $\mathrm{SC} 13$ & Technology Transfer & 2 \\
\hline SC 14 & Other Resource Constraints Met & 1 \\
\hline $\mathrm{SC} 15$ & Meeting Functional Performance & 1 \\
\hline SC 16 & Favorable Impact on Customer, Customer's Gain & 1 \\
\hline SC 17 & Customer Is Using Product & 1 \\
\hline SC 18 & Immediate Business And/or Commercial Success & 1 \\
\hline SC 19 & Immediate Revenue and Profits Enhanced & 1 \\
\hline SC 20 & Larger Market Share Generated & 1 \\
\hline $\mathrm{SC} 21$ & Performance In Terms of Time, Cost, Quality & 1 \\
\hline SC 22 & Project Achieves Its Purpose & 1 \\
\hline $\mathrm{SC} 23$ & Reoccurring Business & 1 \\
\hline SC 24 & Self-Defined Criteria & 1 \\
\hline $\mathrm{SC} 25$ & Top Management Support & 1 \\
\hline SC 26 & Project Contracts & 1 \\
\hline SC 27 & Project Risk Management & 1 \\
\hline SC 28 & Resource Availability & 1 \\
\hline SC 29 & Project Control & 1 \\
\hline SC 30 & Project Change & 1 \\
\hline SC 31 & Sales Of Product & 1 \\
\hline SC 32 & Market Share & 1 \\
\hline SC 33 & Product Profitability & 1 \\
\hline SC 34 & Sustainability & 1 \\
\hline SC 35 & Durability & 1 \\
\hline SC 36 & Capital Gain & 1 \\
\hline SC 37 & Experience/Knowledge Gain from the Project & 1 \\
\hline SC 38 & Improvement of the Management & 1 \\
\hline SC 39 & Company Growth & 1 \\
\hline $\mathrm{SC} 40$ & Personnel Training & 1 \\
\hline $\mathrm{SC} 41$ & Developer-Contractor Relation & 1 \\
\hline SC 42 & Developer's Reputation & 1 \\
\hline
\end{tabular}


Table Continued

\begin{tabular}{|c|c|c|}
\hline SC 43 & Benefit Assessment & 1 \\
\hline SC 44 & Innovation & 1 \\
\hline SC 45 & Uniqueness & 1 \\
\hline SC 46 & Variations & 1 \\
\hline SC 47 & Stakeholder Coordination/ Stakeholder Integration & 1 \\
\hline SC 48 & Business \& Commercial Performance & 1 \\
\hline SC 49 & Strategic Goals/ Objectives \& Competitiveness & 1 \\
\hline SC 50 & Use & 1 \\
\hline SC 51 & Future Perspective & 1 \\
\hline SC 52 & Completion & 1 \\
\hline SC 53 & Absence of Conflicts & 1 \\
\hline SC 54 & Productivity & 1 \\
\hline SC 55 & Professional Image & 1 \\
\hline SC 56 & Aesthetics & 1 \\
\hline SC 57 & Educational, Social \& Professional Aspects & 1 \\
\hline SC 58 & Overall Risk Containment & 1 \\
\hline SC 59 & Risk Containment on Individual House-Units & 1 \\
\hline
\end{tabular}

\section{REFERENCES}

[1] Sanvido, V., Grobler, F., Parfitt, K., Guvenis, M., \& Coyle, M., "Critical Success Factors for Construction Projects," Journal of Construction Engineering and Management, vol. 118, no. 1, pp. 94-111, 1992, DOI: 10.1061/(ASCE)0733-9364(1992)118:1(94).

[2] Saqib, M., Farooqui, R. U., \& Lodi, S. H., "Assessment of Critical Success Factors for Construction Projects in Pakistan," First International Conference on Construction in Developing Countries, Aug. 4-5, 2008, pp. 392-404.

[3] Jari, A., Pankaj, J., \& Bhangale, P., "To Study Critical Factors Necessary for a Successful Construction Project," International Journal of Innovative Technology and Exploring Engineering (IJITEE), vol. 2, no. 5, pp. 331-335, 2013, DOI: 10.1.1.673.8787.

[4] Turner, J. R., "Project management: a profession based on knowledge or faith?," PM Network, vol. 13, no. 10, pp. 41, 1999, https://www.pmi.org/learning/library/project-manag ement-profession-knowledge-faith-5112.

[5] Frefer, A., Mahmoud, M., Haleema, H., \& Almamlook, R., "Overview Success Criteria and Critical Success Factors in Project Management," Journal of Industrial Engineering and Management, vol. 7, no. 1, pp. 1-6, 2018, DOI: 10.4172/2169-0316.1000244.

[6] Chan, A. P., Scott, D., \& Lam, E. W., "Framework of Success Criteria for Design/Build Projects," Journal of Management in Engineering, vol. 18, no. 3, pp. 120-128, 2002, DOI: 10.1061/(ASCE)0742-597X(2002)18:3(120).

[7] Parfitt, M. K., and Sanvido, V. E., "Checklist of critical success factors for building projects," Journal of Management in Engineering, vol. 9, no. 3, pp. 243-249, 1993, DOI: $10.1061 /($ asce $) 9742-597 x(1993) 9: 3(243)$.

[8] Lim, C. S., and Mohamed, M. Z., "Criteria of project success: An exploratory re-examination," International Journal of Project Management, vol. 17, no. 4, pp. 243-248, 1999, DOI: 10.1016/S0263-7863(98)00040-4.

[9] Al-Tmeemy, S., Abdul-Rahman, H., \& Harun, Z., "Future criteria for success of building projects in Malaysia," International Journal of Project Management, vol. 29, no. 3, pp. 337-348, 2011, DOI: 10.1016/j.ijproman.2010.03.003.

[10] Rodrigues, A., \& Bowers, J., "System dynamics in project management: a comparative analysis with traditional methods," System Dynamics Review, vol. 12, no. 2, pp. 121-139, 1996, DOI: 10.1002/(sici)1099-1727(199622)12: $2<121$ ::aid-sdr99>3.0.co;2-x.

[11] Silva, S., Warnakulasuriya, B., \& Arachchige, B., "Critical Success Factors: En Route for Success of Construction Projects," International Journal of Business and Social Science, vol. 7, no. 3, pp. 27-37, 2016, https://ijbssnet.com/journals/Vol_7_No_3_March_2016/4. pdf.

[12] Westerveld, E., "The Project Excellence Model: linking success criteria and critical success factors," International Journal of Project Management, vol. 21, no. 6, pp. 411-418, 2003, DOI: 10.1016/S0263-7863(02)00112-6.

[13] Nicholas, J., "Successful Project Management: A Force-Field Analysis," Journal of Systems Management, vol. 40, no. 1, pp. 24-30, 1989, DOI/10.5555/64522.64526.

[14] Wateridge, J., "IT projects: A basis for success," International Journal of Project Management, vol. 13, no. 3, pp. 169-172, 1995, https://doi.org/10.1016/0263-7863(95) 00020-Q. 
[15] Toor, S.-u.-R., \& Ogunlana, S. O., "Beyond the "iron triangle': Stakeholder perception of key performance indicators (KPIs) for large-scale public sector development projects," International Journal of Project Management, vol. 28, no. 3, pp. 228-236, 2010, DOI: 10.1016/j.ijproman.2009.05.005.

[16] Han, W., Yusof, A., Ismail, S., \& Aun, N., "Reviewing the Notions of Construction Project Success," International Journal of Business and Management, vol. 7, no. 1, pp. 90-101, 2012, DOI: 10.5539/ijbm.v7n1p90.

[17] Ika, L. A., "Project success as a topic in project management journals," Project Management Journal, vol. 40, no. 4, pp. 6-19, 2009, DOI: 10.1002/pmj.20137.

[18] Pinto, J. K., \& Prescott, J. E., "Changes In Critical Success Factor Importance Over the Life of a Project," Academy of Management Proceedings, vol. 1987, no. 1, 2017, https://doi.org/10.5465/ambpp.1987.17534396.

[19] Haughhey, D., "Pareto Analysis Step by Step," https://files.transtutors.com/cdn/uploadassignments/12843 37_1_pareto-analysis-step-by-step.pdf.

[20] Fei, X., \& Khan, T., "Identifying attributes for expert construction project managers in the context of China," International Journal of Asian Social Science, vol. 5, no. 7, pp. 407-418, 2015, https://ideas.repec.org/a/asi/ijoass/2015 p407-418.html.

[21] Saaty, T. L., "The Analytic Hierarchy Process," McGraw-Hill: New York, 1980.

[22] Saaty, T. L., "Decision Making for leaders," IEEE Transactions on Systems, Man, and Cybernetics, vol. 15, no. $3, \quad$ pp. 450-452, 1985, DOI: 10.1109/tsmc. 1985.6313384 .

[23] Lee, S., "Determination of Priority Weights under
Multiattribute Decision-Making Situations: AHP versus Fuzzy AHP," Journal of Engineering Construction and Management, vol. 141, no. 2, pp. 1-9, 2015, DOI: $10.1061 /$ (asce)co.1943-7862.0000897.

[24] Juanzon, J. B., "Expectations and Perceptions in Engineering Consulting Project Management Quality Services: A Gap Analysis Using AHP Method and SERVQUAL Model," International Journal of Innovation, Management and Technology, Vol. 10, No. 1, p.p. 38-42, 2019, DOI: 10.18178/ijimt.2019.10.1.833.

[25] Ereck R. Andal, Joseph Berlin P. Juanzon, "Identifying Risks in Implementing Sustainable Building Materials in Condominium Fit-out Projects Using Analytic Hierarchy Process," Civil Engineering and Architecture, Vol. 8, No. 6, pp. 1266 - 1276, 2020. DOI: 10.13189/cea.2020.080610.

[26] Pirdashti, M., Ghadi, A., \& Mohammadi, M., "An AHP-Delphi Multi-Criteria Usage Cases Model with Application to Citrogypsum Decisions, Case Study: Kimia Gharb Gostar Industries Company," World Academy of Science, Engineering and Technology, International Journal of Chemical, Molecular, Nuclear, Materials and Metallurgical Engineering, vol. 3, pp. 97-103, 2009, https://www.semanticscholar.org/paper/An-AHP-DelphiMulti-Criteria-Usage-Cases-Model-with-Pirdashti-Omidi/8 5bb753dcb86ad53b75adaa8f350922965a70639.

[27] Forman, E., \& Selly, M., "The Analytic Hierarchy Process and Expert Choice," in Decision by Objectives: How to Convince Others That You are Right, World Scientific Books, World Scientific Publishing Co. Pte. Ltd., 2001, pp. 43-125.

[28] Suner A, Çelikoğlu CC, Dicle O, Sökmen S., "Sequential decision tree using the analytic hierarchy process for decision support in rectal cancer," Artif Intell Med, vol. 56, no. 1 , pp. 59-68, 2012, DOI: 10.1016/j.artmed.2012.05.003. 